\title{
Analysis of a Two-Body Floating Wave Energy Converter With Particular Focus on the Effects of Power Take-Off and Mooring Systems on Energy Capture
}

\author{
Made Jaya Muliawan Zhen Gao, Torgeir Moan \\ Centre for Ship and Ocean Structures (CeSOS), Norwegian University of Science and Technology, Otto Nielsens vei 10, NO-7491, \\ Trondheim, Norway
}

Aurélien Babarit

LUNAM Université,

Ecole Centrale de Nantes, LHEEA Lab. - CNRS UMR6598, 1, rue la Noë, Nantes 44300, France

\begin{abstract}
The present paper summarizes analyses of a two-body floating wave energy converter (WEC) to determine the mooring tension and the effect of the mooring system on energy capture. Also, the effect of the power take-off (PTO) is assessed. An axisymmetric Wavebobtype WEC is chosen as the object of investigation. However, the PTO system is modeled in a simplified manner as ideal linear damping and spring terms that couple the motions of the two bodies. The analysis is performed using SIMO, which is a time domain simulation tool that accommodates the simulation of multibody systems with hydrodynamic interactions. In SIMO, docking cone features between the two bodies allow movement as per actual operation, and fenders are applied to represent end stops. Six alternative mooring configurations are applied to investigate the effect of mooring on power capture. Mooring analysis is performed to determine the necessary capacity of mooring lines for each configuration to carry the tension due to the WEC motion in extreme conditions. Hydrodynamic loads are determined using WAMIT. We assumed that the WEC will be operated to capture wave power at the Yeu site in France. The analysis is performed for several regular and irregular wave conditions according to wave data available for that site. Simulations are performed to study the effect of the PTO system, end stops settings and several mooring configurations on power capture.
\end{abstract}

\section{Introduction}

Ocean waves are a nonharvested source of renewable energy. The technology for the extraction of energy from waves remains in the research and development stage, although dedicated research in this field began in the 1970 s. It has been difficult to convert this energy in an efficient and profitable manner. However, it is normal that the development of a new technology takes time, and today several development projects are beginning to reach a level of maturity in which large-scale production will be possible.

Among the presently available types of wave energy converters (WECs), French [1] considered several floating WECs that consist of two-body systems as promising. In this kind of two-body WEC, the power take-off (PTO) is from the relative motion, and the analysis of the motions of multibodies with hydrodynamic coupling is crucial for the estimation of power capture. The introduction of a PTO system that connects two bodies with damping and stiffness terms also needs to be evaluated to manage the motion and optimize the power. Moreover, possible end stops to limit the relative motions between two bodies, which could be modeled as a nonlinear stiffness, increases the complexity of the analysis.

In addition, this type of WEC, like other floating structures, requires a mooring system to remain stationary. The mooring system directly affects the motions and the power that is captured by the WEC. Fitzgerald et al. [2] demonstrated how the power that is absorbed by a single floater WEC influences the choice of the

Contributed by the Ocean, Offshore, and Arctic Engineering Division of ASME for publication in the Journal of Offshore Mechanics and Arctic Engineering. Manuscript received May 30, 2011; final manuscript received October 17, 2012; published online May 24, 2013. Assoc. Editor: Hideyuki Suzuki. type of mooring cable and its layout. Because the present WEC is a two-body system, the effect of the mooring system on power capture must be investigated.

Therefore, the purpose of this paper is to examine the power capture of this WEC both in regular and irregular waves. An axisymmetric Wavebob-type system is chosen as the device considered in the present study to investigate the effects of varying of PTO coefficients, end stops settings, and the application of several different catenary mooring configurations on power production. The present study is based on available information in the open literature and assumptions made by the authors. Therefore, there may be differences between the WEC analyzed in this paper and that of the Wavebob project.

\section{Axisymmetric Wavebob-Type WEC}

According to the Wavebob's website [3], the WEC is an axisymmetric, self-reacting point absorber that primarily operates in the heave mode. It consists of two concentric bodies with different heave frequencies, which are called Torus for the shallower body and Float for the deeper body as illustrated in Fig. 1. In the present analysis, the dimensions and properties of the system shown in Fig. 2 and Table 1 have been used. These data were obtained or estimated from available published information and may deviate from the true Wavebob concept.

Wavebob uses a hydraulic PTO system to transform energy from waves to electricity [3]. However, simplifications are made in the present analysis because it is assumed that the PTO system will be controlled to behave like an ideal linear damper and spring systems, which are referred to as Bpto and Kpto, respectively. Wavebob with a hydraulic PTO system has the possibility to control the response by controlling the amount of the mass that is 


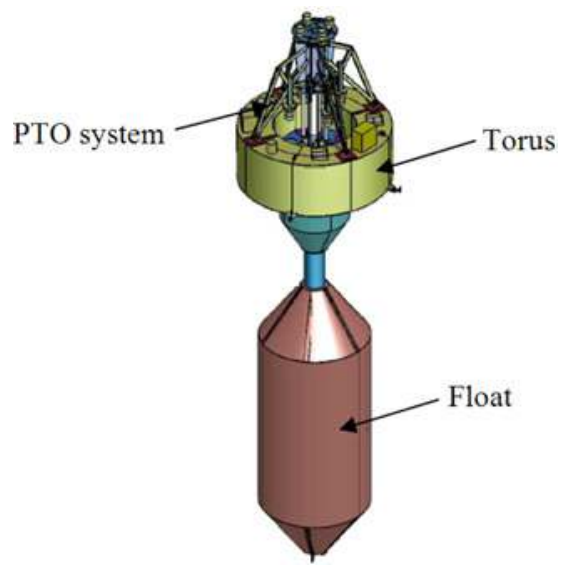

Fig. 1 Wavebob concept [4]

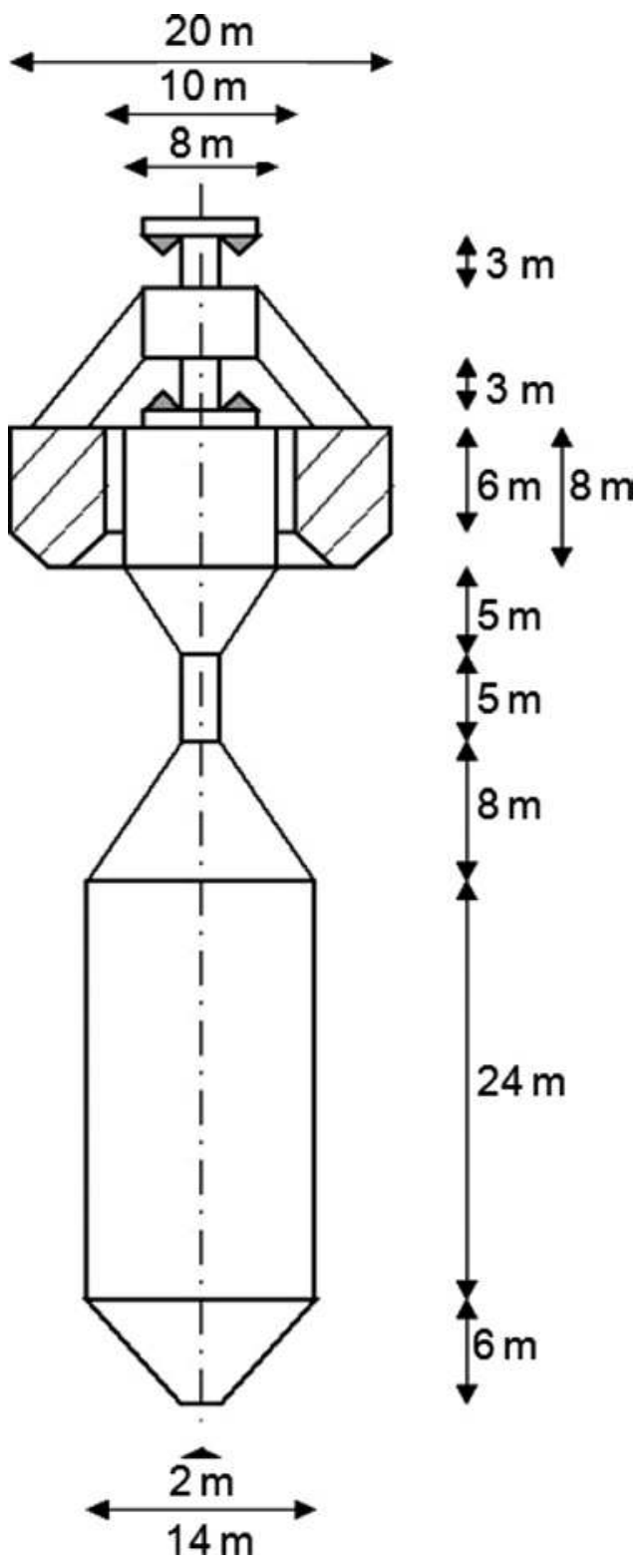

Fig. 2 Dimensions of the WEC used in the present analysis
Table 1 Parameters of the WEC system used in the present analysis

\begin{tabular}{|c|c|c|}
\hline Property & Value & Unit \\
\hline \multicolumn{3}{|l|}{ Torus } \\
\hline Outer diameter & 20 & $\mathrm{~m}$ \\
\hline Inner diameter & 10 & $\mathrm{~m}$ \\
\hline Draft & 2 & $\mathrm{~m}$ \\
\hline Height & 8 & $\mathrm{~m}$ \\
\hline Displacement & 278 & $\mathrm{~m}^{3} \mathrm{~s}$ \\
\hline Mass & 278 & tons \\
\hline Center of mass & 0 & $\mathrm{~m}$ below the free surface \\
\hline Moment of inertia $I_{x x}$ & 12,400 & tons $\mathrm{m}^{2}$ \\
\hline Moment of inertia $I_{y y}$ & 12,400 & tons $\mathrm{m}^{2}$ \\
\hline Moment of inertia $I_{z z}$ & 16,500 & tons $\mathrm{m}^{2}$ \\
\hline Stroke length & 6 & $\mathrm{~m}$ \\
\hline Stiffness upper end stop spring & $10^{6}$ & $\mathrm{kN} / \mathrm{m}$ \\
\hline Stiffness lower end stop spring & $10^{6}$ & $\mathrm{kN} / \mathrm{m}$ \\
\hline \multicolumn{3}{|l|}{ Float } \\
\hline Diameter at water level & 8 & $\mathrm{~m}$ \\
\hline Draft & 50 & $\mathrm{~m}$ \\
\hline Height & 66 & $\mathrm{~m}$ \\
\hline Displacement & 4,680 & $\mathrm{~m}^{3}$ \\
\hline Mass & 4,680 & tons \\
\hline Center of mass & -35 & $\mathrm{~m}$ below the free surface \\
\hline Moment of inertia $I_{x x}$ & $1,740,000$ & tons $\mathrm{m}^{2}$ \\
\hline Moment of inertia $I_{y y}$ & $1,740,000$ & tons $\mathrm{m}^{2}$ \\
\hline Moment of inertia $I_{z z}$ & $1,510,000$ & tons $\mathrm{m}^{2}$ \\
\hline
\end{tabular}

transferred from the Float to the Torus. Therefore, the parameter called Mpto is included in the present analysis to represent the transferred mass, and the effect of this parameter on power capture is investigated.

\section{Mooring Configurations and Analysis}

The six different mooring configurations that are presented in Fig. 3 and summarized in Table 2 are included in the study. Each configuration consists of four steel wire lines arranged in a symmetric manner as shown in Fig. 3. Mooring analysis is performed to find mooring lines capable of facing the forces during extreme conditions that may occur at an operation site. In this study, the Yeu site $\left(046 \mathrm{deg} 40,000^{\prime} \mathrm{N}-022 \mathrm{deg} 25,000^{\prime} \mathrm{W}\right)$ in France that is shown in Fig. 4(a) is considered to be the operational site. The distribution of wave height and period at this location based on a full year of real sea measurements [5] is illustrated in Fig. 4(b).

As a new and a unique system, the criteria for the design of the WEC mooring system are not yet available. Therefore, practices from the oil and gas industry (e.g., DNV-OS301 [7]) are referred to in the present paper. Only the ultimate limit state (ULS) criteria is considered in the present mooring analysis. However, the applicability of the accidental limit state (ALS) criteria to the

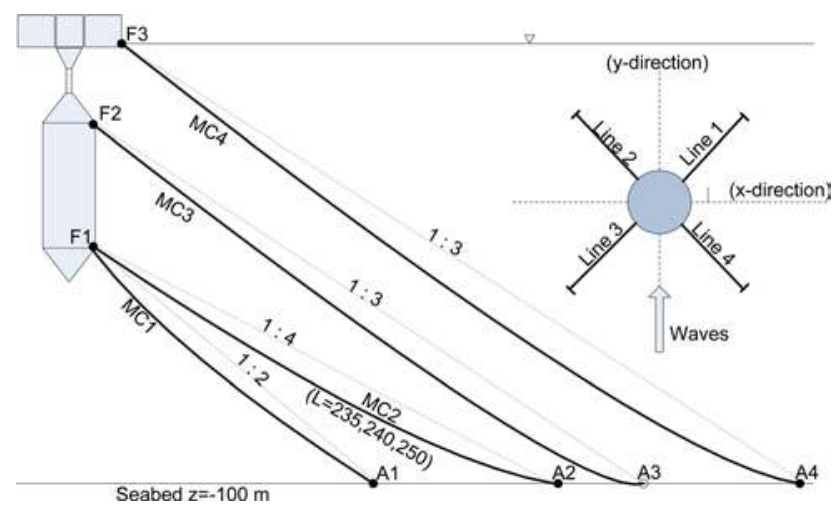

Fig. 3 Mooring configurations that are used in the simulations 
Table 2 Summary of mooring configurations (line 1 only-symmetric for other lines) shown in Fig. 3

\begin{tabular}{|c|c|c|c|c|c|c|c|c|c|}
\hline \multirow[b]{2}{*}{ Mooring configuration } & \multicolumn{3}{|c|}{ Fairlead coordinate $(F)$} & \multicolumn{3}{|c|}{ Anchor coordinate $(A)$} & \multirow{2}{*}{$\frac{\text { Slope }}{1: \mathrm{m}}$} & \multirow[b]{2}{*}{ Distance $A-F(\mathrm{~m})$} & \multirow[b]{2}{*}{ Line length (m) } \\
\hline & $\mathrm{x}$ & $\mathrm{y}$ & $\mathrm{z}$ & $\mathrm{x}$ & $\mathrm{y}$ & $\mathrm{z}$ & & & \\
\hline MC1 & 4.9497 & 4.9497 & -44 & 85 & 85 & -100 & 2 & 125.22 & 130 \\
\hline $\operatorname{MC} 2(L=235 \mathrm{~m})$ & 4.9497 & 4.9497 & -44 & 165 & 165 & -100 & 4 & 230.89 & 235 \\
\hline $\operatorname{MC} 2(L=240 \mathrm{~m})$ & 4.9497 & 4.9497 & -44 & 165 & 165 & -100 & 4 & 230.89 & 240 \\
\hline $\operatorname{MC} 2(L=250 \mathrm{~m})$ & 4.9497 & 4.9497 & -44 & 165 & 165 & -100 & 4 & 230.89 & 250 \\
\hline MC3 & 4.9497 & 4.9497 & -20 & 175 & 175 & -100 & 3 & 252.98 & 260 \\
\hline MC4 & 7.071 & 7.071 & 0 & 220 & 220 & -100 & 3 & 316.23 & 320 \\
\hline
\end{tabular}

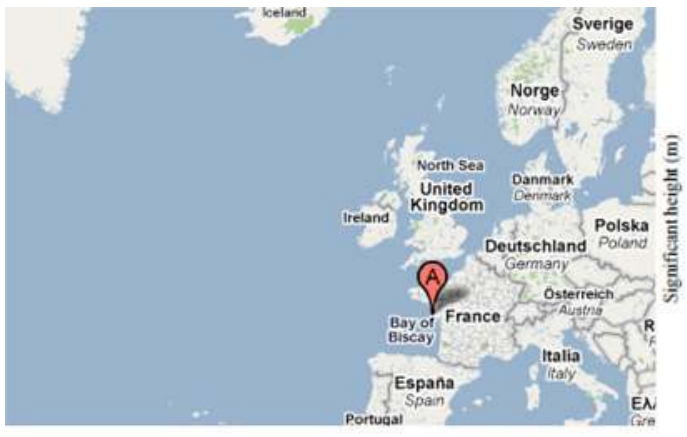

(a)

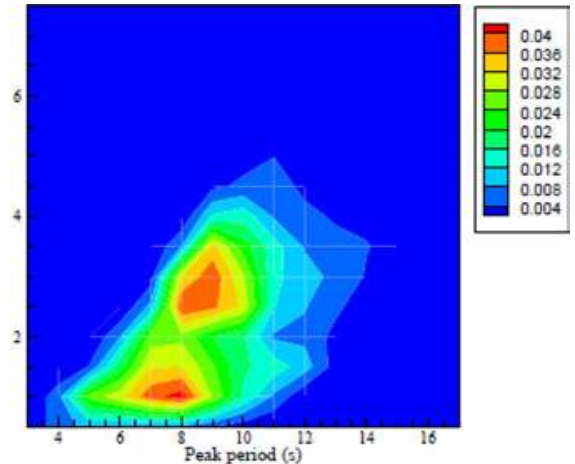

(b)

Fig. 4 (a) Location of the Yeu site specified as "A" [6] and (b) scatter diagram of waves at the Yeu, in France

mooring systems for WEC should also be considered. ALS might include a check of the ability to carry the tension even if one of the lines fail. Because fatalities and pollution would not be consequences of a failure of the mooring system of WECs, economic criteria would be decisive for the determination of safety levels and whether ALS criteria should be applied.

The contour line method [8] is used to estimate long-term extreme mooring tension. The contour line method is assumed to be valid for the WEC. According to [7], the environmental loads for mooring line response calculations should be based on the wind and wave conditions in a 100-year return period and applied with currents in a 10-year return period. However, only waves are considered as the environmental load applied in the current study, although in general, waves from different directions should be considered. However, as shown in Fig. 4(a), the Yeu site is mostly surrounded by other lands, except in the west. According to this situation, the mooring configuration is set to the orientation of the incoming waves as illustrated in Fig. 3 to minimize the line tension. It is assumed here that the long-term variation of sea states is described by a joint distribution in which the spectral peak period follows a log-normal distribution and the significant wave height follows a Weibull distribution. Therefore, the 100-year contour line can be depicted as shown in Fig. 5, which represents a set of combinations of significant wave height and peak periods that have similar 100-year probabilities.

During extreme conditions, the survival of the WEC systems becomes more important than the expectation that the WEC absorbs power. There are some alternatives of the survival strategy that could be applied for this type of WEC. One possibility is the introduction of a locking system in the interface between the two bodies to minimize the instantaneous force that is experienced by the PTO system. This survival strategy is considered here, but this application ignores the wave power from the sea state that is higher than sea state introduced in this setting. The choice of this strategy, which includes this setting, will actually be the decision results from the optimization process of the overall WEC project. However, for the purpose of the present mooring analysis, it is

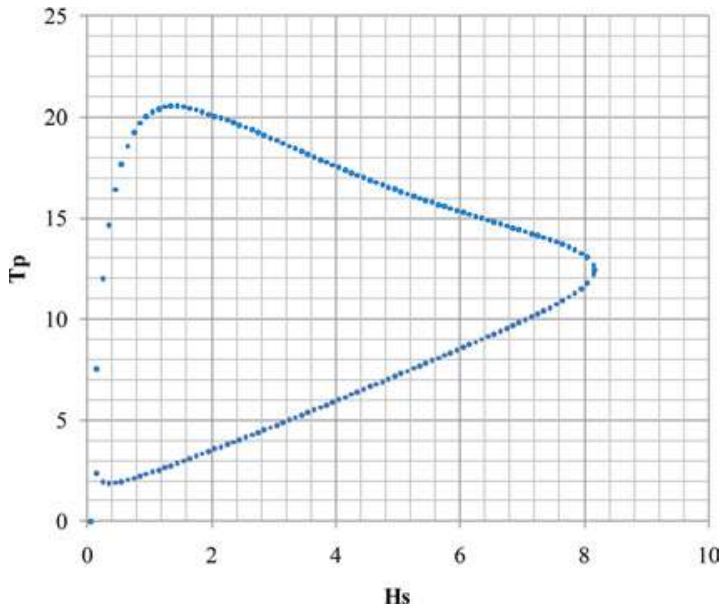

Fig. 5 100-year contour line for the wave conditions at the Yeu site

assumed that the Float and the Torus are locked in the mean position during the extreme conditions of $H_{s}>6 \mathrm{~m}$ and $T_{p}>12 \mathrm{~s}$ and hence for the 100-year conditions. Therefore, the two-body WEC could be modeled as a single body. Hydrodynamic properties, including first and second order wave forces based on a single system, are calculated in the frequency domain using HydroD [9] based on WAMIT [10] as the core approach for the hydrodynamic analysis. These hydrodynamic properties are applied in the mooring analysis for different mooring configurations using time domain simulation with SIMO/Riflex [11] that includes the stiffness, mass, and viscous forces on the lines due to its motion and fluid interaction. According to the Morison model, viscous forces on the WEC body are also included during the mooring analysis. Figure 6 shows the RAOs of the locked body (a single body) for the heave, sway, and pitch motions results from the hydrodynamic 


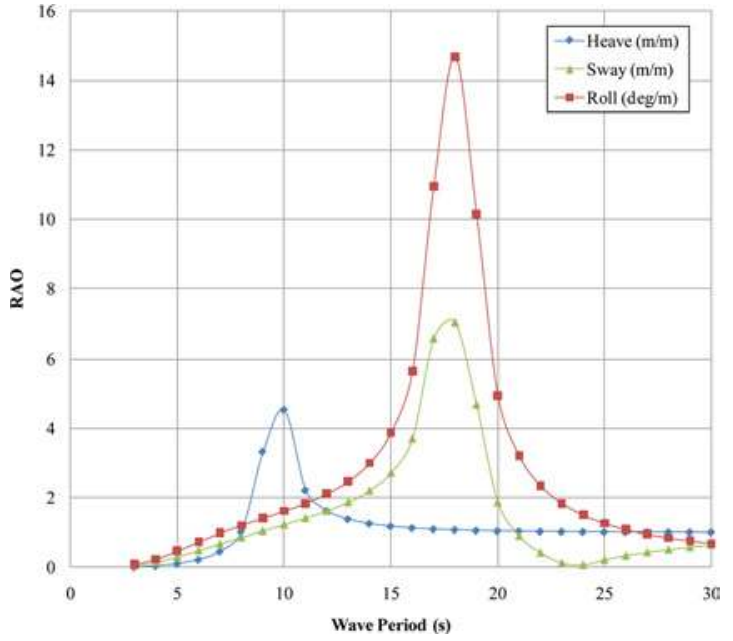

Fig. 6 RAOs of the WEC for heave, sway, and roll motions when the float and the torus are locked

analysis. Figure 6 shows that the natural periods of the single body WEC are $10 \mathrm{~s}$ for heave and $18 \mathrm{~s}$ for roll motion. Sway RAO also shows a peak of $18 \mathrm{~s}$, which is due to the coupling with the roll motion.

The mooring analyses are performed by considering some combinations of significant wave height and peak period on the 100-year contour line in Fig. 5. It is assumed that wave conditions are represented by a Jonswap wave spectrum with parameter $\gamma=3.3$. Maximum tensions are produced when an $H_{s}=8.16 \mathrm{~m}$ and a $T_{p}=12.43 \mathrm{~s}$ among the sea states on the contour line is applied. Therefore, in this paper, only the results of the analysis from the application of this sea state are presented. Figure 7 shows the examples of the time series for the line tensions in the mooring system.

Except for MC2 $(L=240 \mathrm{~m})$ and $\operatorname{MC} 2(L=250 \mathrm{~m})$, all of the configurations that are specified in Table 2 are considered in the mooring analysis. It is expected that $\mathrm{MC} 2(L=235 \mathrm{~m})$, which has the shortest lines of the MC2 configurations, will experience the highest line tensions. Therefore, the mooring line dimension from the MC2 $(L=235 \mathrm{~m})$ results of the analysis will also be sufficient for both the MC2 $(L=240 \mathrm{~m})$ and $\mathrm{MC} 2(L=250 \mathrm{~m})$. By performing the mooring analyses in 12 different 1 -h simulations using 12 different extreme wave realizations for each mooring configuration, the distribution of 1-h maximum line tensions can be plotted

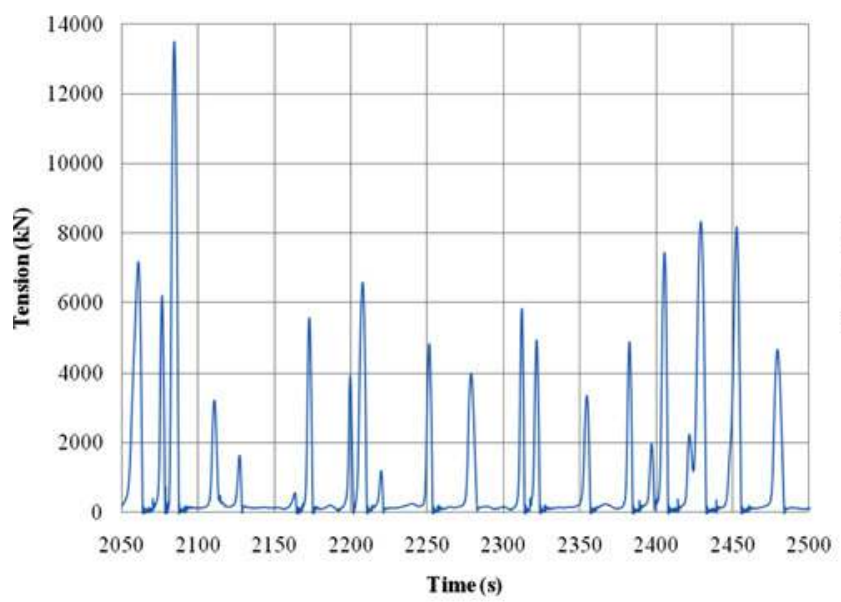

(a) by fitting the simulation results to a Gumbel distribution as shown in Fig. 8(a). These 1-h distributions are used to estimate the 3-h maximum tension distributions that are presented in Fig. 8(b), assuming that the 3 -h period contains three independent 1-h extremes. When contour lines are applied, long-term extreme line tensions that correspond to $10^{-2}$ annual exceedance probability for each mooring configuration should be estimated by taking a higher percentile than the median tension of the 3-h distributions as stated in NORSOK N-003 [12]. This estimation is required to artificially account for the variability of the short-term extreme value. The percentile level depends slightly on the nature of the response problem, i.e., the degree of nonlinearity and the number of important slowly varying parameters, but a choice of the $90 \%$ percentile has been used in the present analysis as recommended by Haver et al. [13]. Certainly, this choice needs to be validated by long-term analysis results when applied for the WEC. However, this validation has been sustained as part of an ongoing study of the author.

The estimated long-term extreme tensions and its corresponding required steel wire line dimensions for each mooring configurations are summarized in Table 3 as the results of the mooring analysis in this study. The lines dimensions in Table 3 are chosen to fulfill the design criteria mentioned in [7] by the application of a safety factor of 1.5 on dynamic line tensions and the use of $95 \%$ line breaking strength. Line properties, such as submerged weight, axial stiffness, and the breaking strength for corresponding line diameters, are estimated by referring the line properties to the table by Johanning et al. [14]. Applied line dimensions for each mooring configuration that is specified as "Applied $\varnothing$ " in Table 3 with its correspondent properties are introduced in the model to observe the effect of each mooring configuration on the power absorption of the WEC.

\section{Two-Body System Modeling and Analysis}

The present analysis is performed in the time domain using SIMO [15]. SIMO is a computer program that was developed by Marintek for simulating motions and station-keeping behavior of complex systems of floating vessels and suspended loads. SIMO's essential features for the present analysis is its flexible modeling of multibody systems that accommodate the introduction of Kpto, Bpto, end stops, and hydrodynamic coupling between Float and Torus. Two-body hydrodynamic properties, including its interactions, are calculated in the frequency domain using HydroD and then applied in SIMO to solve the motions of two bodies in a given sea state in a time domain. Figure 9 shows the panel model

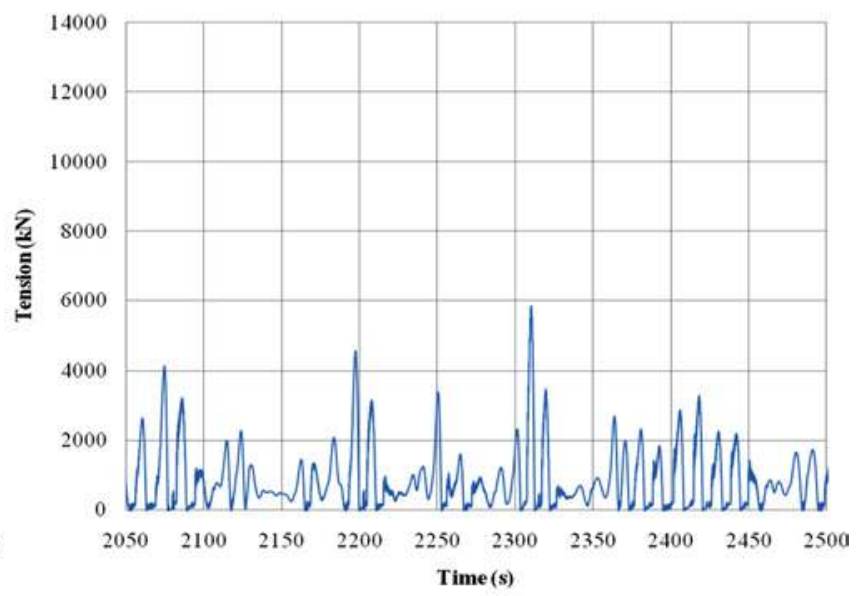

(b)

Fig. 7 Time series of line tensions (a) line no. 4 of MC1 and (b) line no. 4 of MC4 configurations. Sea state when $H_{s}=8.16 \mathrm{~m}$ and $T_{p}=12.43 \mathrm{~s}$ is applied. 


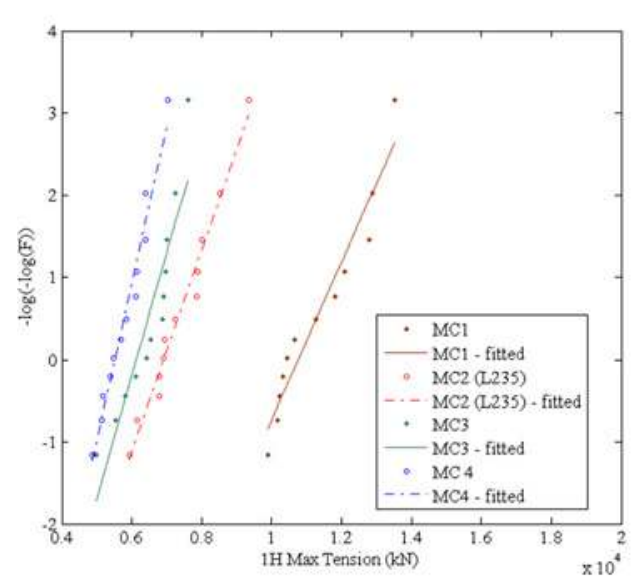

(a)

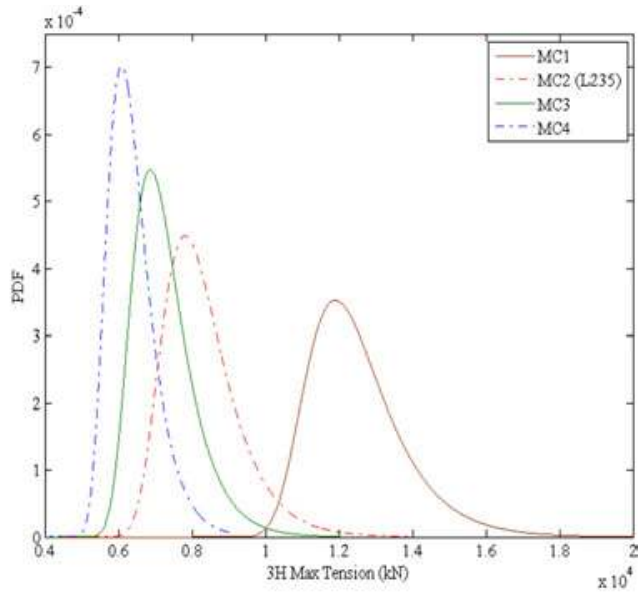

(b)

Fig. 8 Distributions of (a) 1-h and (b) 3-h maximum line tensions for different mooring configurations

Table 3 Summary of line tensions and steel wire line properties for each mooring configuration result from the mooring analysis ${ }^{a}$

\begin{tabular}{lccccccc}
\hline \hline Mooring configuration & $\begin{array}{c}\text { Tension }(\mathrm{kN}) \\
(\mathrm{T})\end{array}$ & $\begin{array}{c}\text { TxSF } \\
(\mathrm{kN})\end{array}$ & $\begin{array}{c}\text { Minimum BS }(\mathrm{kN}) \\
(\mathrm{TxSF}) / \mathrm{BSF}\end{array}$ & $\begin{array}{c}\text { Minimum } \varnothing \\
(\mathrm{cm})\end{array}$ & $\begin{array}{c}\text { Applied } \varnothing \\
(\mathrm{cm})\end{array}$ & $\begin{array}{c}\text { EA } \\
(\mathrm{kN})\end{array}$ & $\begin{array}{c}\text { Submerged weight } \\
(\mathrm{N} / \mathrm{m})\end{array}$ \\
\hline MC1 & 14,250 & 21,375 & $22,500.0$ & 19.4 & 19.5 & $1,711,125$ & 1292.85 \\
MC2 (L235) & 9,660 & 14,490 & $15,252.6$ & 15.9 & 16 & $1,152,000$ & 870.4 \\
MC3 & 8,380 & 12,570 & $13,231.6$ & 14.9 & 15 & $1,012,500$ & 765 \\
MC4 & 7,265 & $10,897.5$ & $11,471.1$ & 13.8 & 14 & 882,000 & 666.4 \\
\hline \hline
\end{tabular}

${ }^{\mathrm{a}} \mathrm{SF}$ ( safety factor) $=1.5 ; \mathrm{BSF}$ (breaking strength factor) $=0.95 ; \emptyset=$ line diameter.
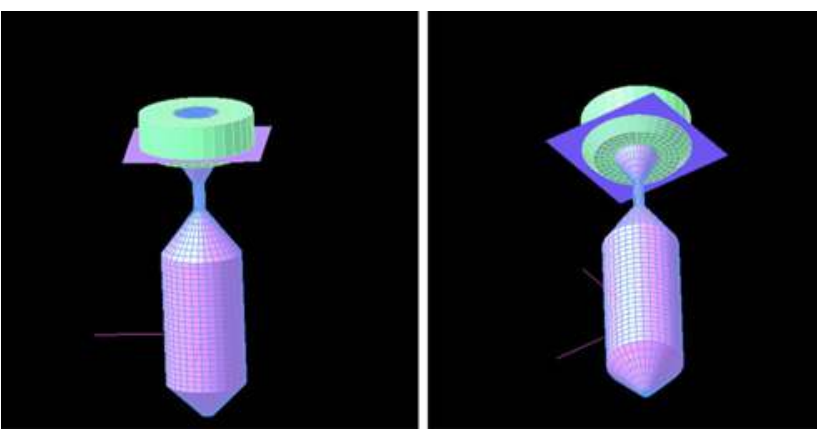

Fig. 9 Panel model in the present analysis

that was developed for the two-body hydrodynamic analysis in the present study.

If the PTO system is not included, each Torus and Float will move freely in heave and yaw, but they will move together in sway, surge, roll, and pitch. These constraints in motions are modeled using the docking cone features that are available in SIMO. At least two docking cone models should be present at every simulation step to ensure that both bodies move together in roll and pitch. In the present model, three docking cone models at three different levels have been introduced as illustrated in Fig. 10 to ensure that at least two springs are working at same time, especially during the high sea state condition. The stiffness parameter presented in Fig. 11 is used for each docking cone. As shown in Fig. 11, a small gap between the Float and Torus is introduced before a very high stiffness coefficient is activated. From some of the photos observed in [3], this gap is actually present in the real Wavebob-type WEC. However, this paper will not deal with this aspect, and there will be no further discussion about this gap and its effect on the response.

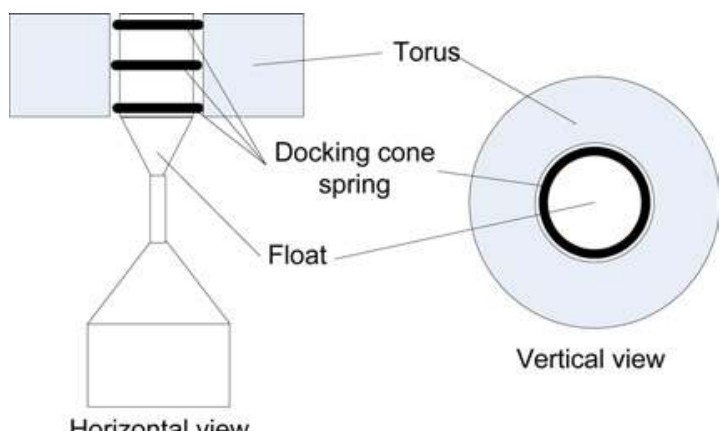

Fig. 10 Introduction of docking cone springs to let the two bodies move together in sway, surge, roll, and pitch yet move freely in heave and yaw

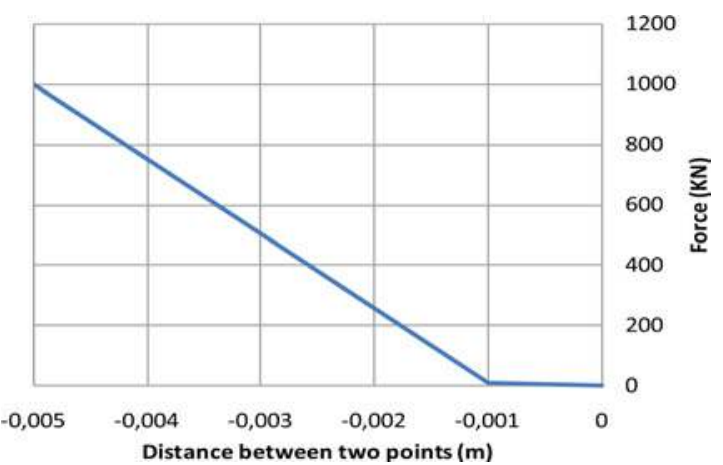

Fig. 11 Stiffness parameter applied for every docking cone in simulation 


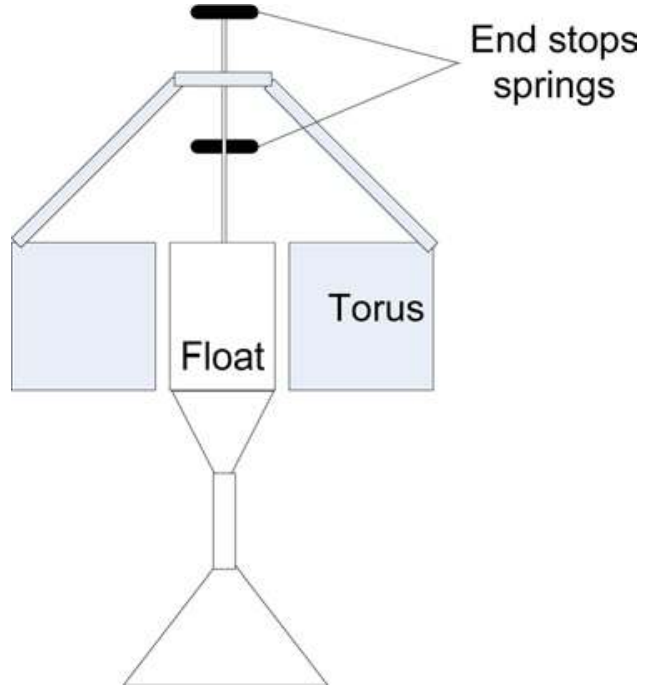

Fig. 12 Introduction of end stop springs to limit the relative vertical motion between the Float and Torus

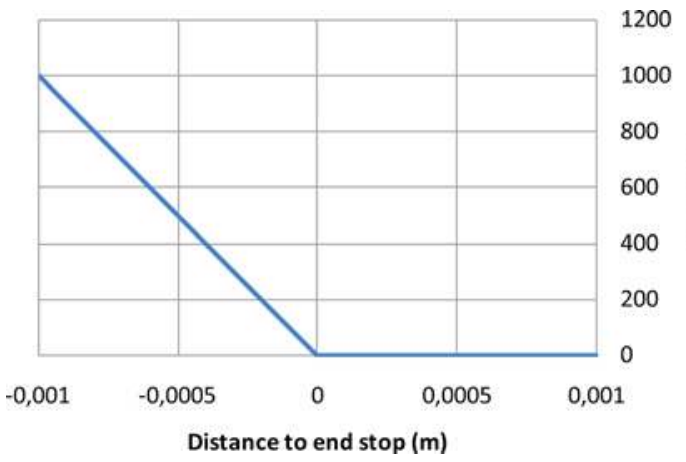

Fig. 13 Restoring coefficient condition applied in each end stop model in simulation

Wavebob-type WEC has two end stops that limit relative vertical motion between the Torus and the Float. These end stops are modeled in the present simulations by the application of fenders in SIMO with a large restoring coefficient at each position of end

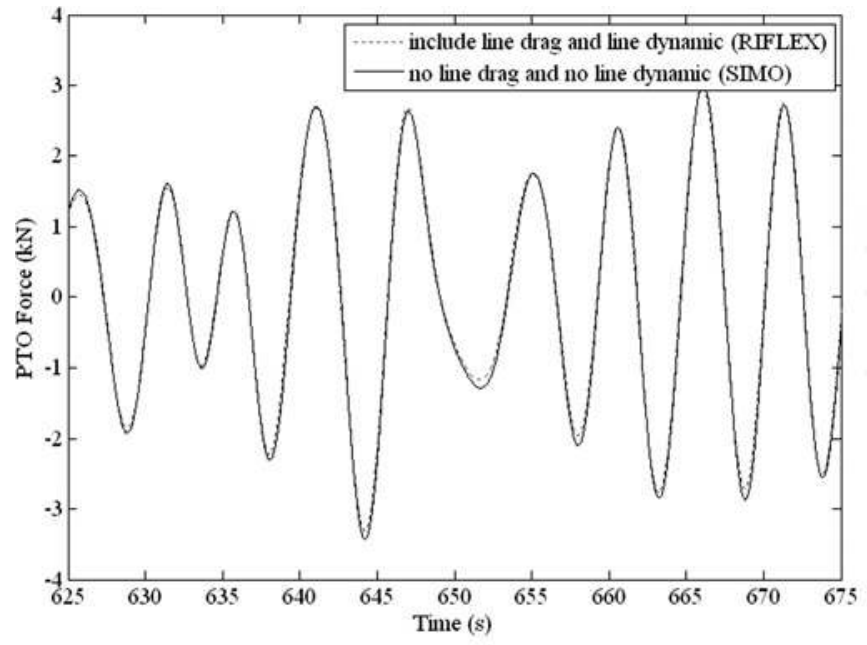

(a) stops. The introduction of the fender model and its stiffness parameter are presented in Figs. 12 and 13, respectively. Unless specified, a stroke of $\pm 3 \mathrm{~m}$ is used in simulations, as described in Table 1.

The PTO system is modeled as an ideal linear damper with coefficient Bpto and linear stiffness coefficient Kpto connecting the Float and Torus. This model will result in the internal forces in the system where the force related to Bpto is proportional to the relative velocity and the force related to Kpto is proportional to the relative motion between the two involved bodies. For a given sea state, the relative motion and the relative velocity between the Float and the Torus will depend on the values of Bpto and Kpto (together with end stops setting). This system implies that the power that is captured by the WEC can simply be estimated using the total force associated with these two terms and the relative velocity between the two bodies. Additionally, Mpto term that represents the transferred mass from the Float to the Torus is included. It is treated as an additional mass to the Torus and mass reduction for the Float; therefore the total mass of the WEC is kept constant. Mpto will change the mean position of the two bodies and inertia forces of the system.

The effect of the mooring system on power capture is studied by the introduction of a simple mooring model in SIMO that works like nonlinear springs but neglects drag and inertia forces due to line motion. The choice of SIMO rather than another program code, such as SIMO/Riflex [11] that includes drag and inertia forces on the lines, is made due to the feature in SIMO that allows for the hydrodynamic coupling between two bodies. This feature is essential in the analysis of power capture. To support this choice, a comparison has been made between SIMO and Riflex without hydrodynamic coupling in both models. Only Bpto is included for the comparison. SIMO provides very good predictions of motions and PTO forces that will be used to estimate power directly, but it underestimates the mooring tension. This comparison indicates that the effect of the drag and inertia forces on the lines is negligible for the PTO force estimation. However, they are important for the mooring system design. Typical comparisons for dynamic PTO forces and mooring tensions between these codes are presented in Fig. 14.

\section{Simulation Setting and Results}

General. In the present study, the simulations to estimate the power are performed based on first order wave forces, both for regular and irregular waves, for a device with and without

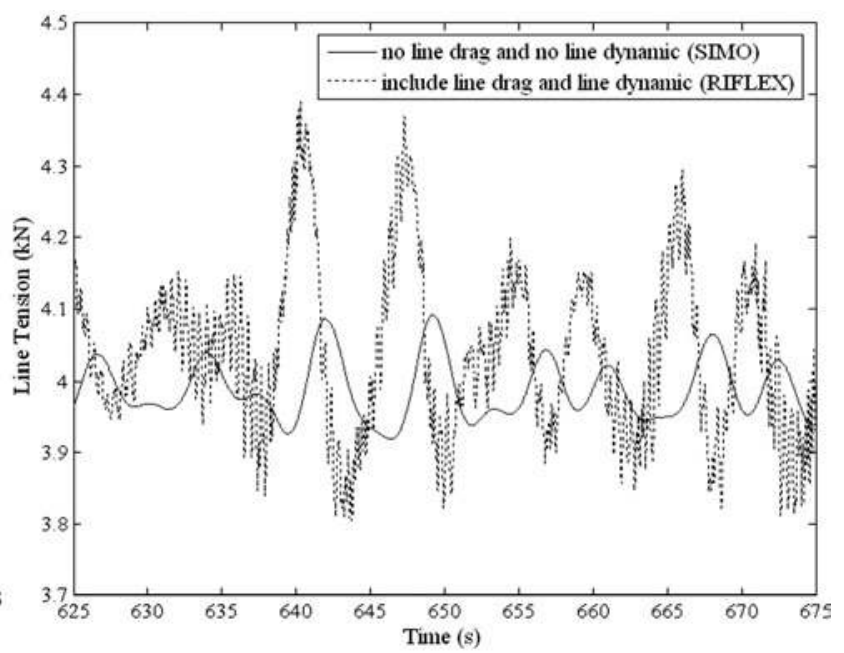

(b)

Fig. 14 Comparisons of (a) PTO force and (b) line tension obtained from Riflex and SIMO for Wavebob-type WEC with mooring but without hydrodynamic interaction between the two bodies 


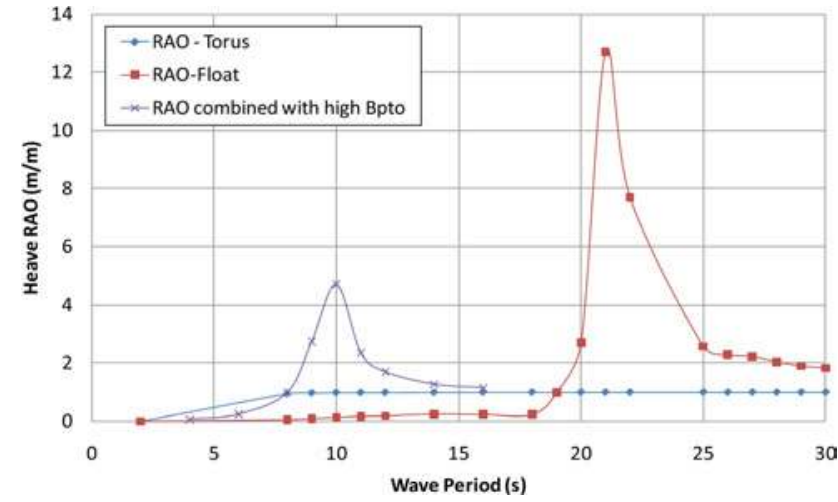

Fig. 15 Heave RAO of Torus and Float separately and combined heave RAO when they are connected with very high Bpto $($ Kpto $=$ Mpto $=0)$

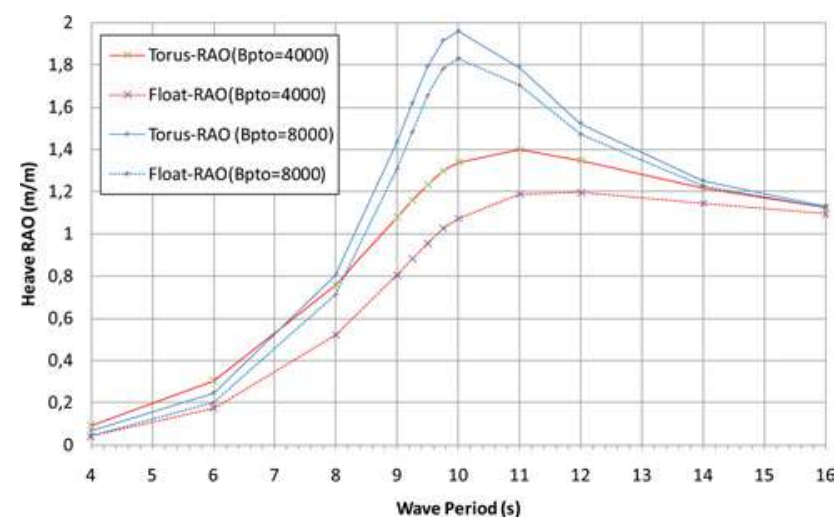

Fig. 16 Heave RAO of Torus and Float when they are connected with different Bpto coefficient $(\mathrm{Kpto}=\mathrm{Mpto}=\mathbf{0})$

mooring. A water depth of $100 \mathrm{~m}$ is used. Simulations under regular waves are mostly performed to determine how PTO parameters, end stops, and mooring configuration affect the power absorption in different waves properties. Simulations under irregular waves are performed to estimate the effect of mooring on annual power production. To ensure that there will be no nonlinear properties other than those from end stops and mooring, no viscous forces are applied on the WEC body in the present simulations.

Response in Regular Waves Without Mooring. The present type of WEC primarily relies on heave mode in its operation. Therefore, it is necessary to study the RAO of heave motion for both the Float and Torus with the dimension and properties given in Table 1. All the RAOs that are presented in this paper are obtained by running time-domain simulations. The simulation results in Fig. 15 show the different heave natural periods for these two bodies. A Torus that has a very large water plane area and relatively small mass has a small natural period, but this is not presented in the figure of the selected wave periods during the simulation. With a small water plane area and very large mass, the natural period of the Float is large. However, when a very high PTO damping Bpto is introduced in the interface between the Float and the Torus, they move together in heave and have a combined heave natural period of approximately $10 \mathrm{~s}$ in the present case study. This is consistent with the frequency domain results that are shown in Fig. 6, which is based on the hydrodynamic analysis of the locked WEC.

Other simulations are performed to see how the heave RAO of those two bodies behaves if the Bpto is changed. The results are
Table 4 Simulation sets to observe

\begin{tabular}{lccc}
\hline \hline Simulation set & Bpto $(\mathrm{kN} / \mathrm{m} \mathrm{s})$ & Kpto $(\mathrm{kN} / \mathrm{m})$ & Mpto (ton) \\
\hline 1 & 1,000 & 0 & 0 \\
2 & 2,000 & 0 & 0 \\
3 & 4,000 & 0 & 0 \\
4 & 8,000 & 0 & 0 \\
5 & 12,000 & 0 & 0 \\
6 & 14,000 & 0 & 0 \\
7 & 4,000 & 1000 & 0 \\
8 & 4,000 & 2000 & 0 \\
9 & 4,000 & 3000 & 0 \\
10 & 4,000 & 4000 & 0 \\
11 & 4,000 & 0 & 200 \\
12 & 4,000 & 0 & 400 \\
13 & 4,000 & 0 & 600 \\
14 & 4,000 & 0 & 800 \\
\hline \hline
\end{tabular}

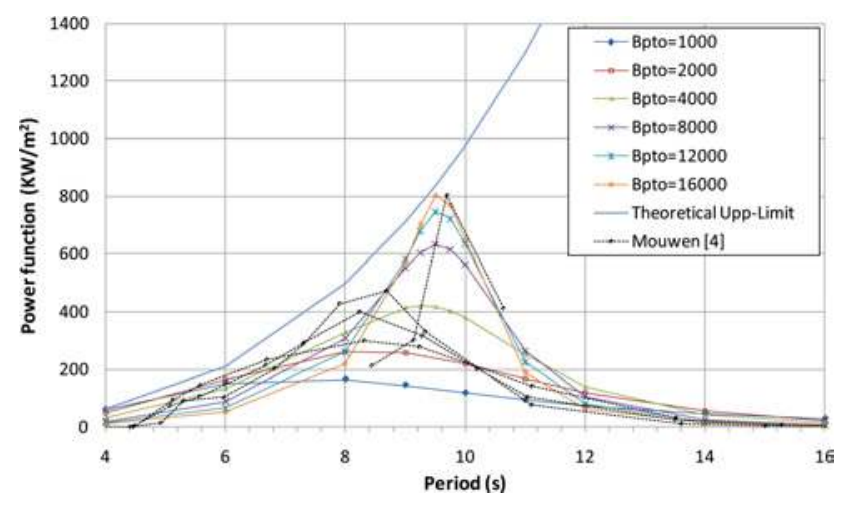

Fig. 17 The power function as a function of the Bpto coefficients $(K p t o=$ Mpto $=0$ ) based on simulation sets 1 to 6 in Table 3 and set results from Mouwen [4]

presented in Fig. 16. It is clear that value of the PTO coefficient sensitively influences the behavior of the motion that is expected to produce power. Therefore, further investigations are performed by simulating the cases that are given in Table 4 to evaluate how each PTO component could be controlled to maximize power production. The values of PTO parameters set in Table 4 are considered to be applicable for the present type of WEC. Bpto values are managed by sizing the actuators and their control. Positive values of Kpto could be achieved by adding a physical spring in the PTO system. Mpto values that represent the transferred mass from the Float to the Torus that could be achieved by adjusting ballast in the both bodies. The volume of the Torus has been considered to define the maximum value of the Mpto in Table 4.

The results from these sets are presented in Figs. 17-19, where the power function indicates the WEC's average absorbed power normalized by the squared of wave amplitude. Figure 17 shows that an increase in Bpto will increase the peak of power to higher levels and will shift the peak to a higher wave period. This peak shifting occurs up to a Bpto coefficient of $8000 \mathrm{kN} \mathrm{s} / \mathrm{m}$. For values higher than this value, no shifting is observed, but the peak of power increases to a theoretical maximum that is calculated using Eq. (1) as described by Budal and Falnes [16]. However, an increase in Bpto results in a narrower bandwidth of the system. This feature is not desirable for WECs.

No experimental results are available at the present time. However, in order to verify the present simulation results, a set of results from Mouwen [4] were added in Fig. 17 for comparison. One can see that present simulations produce very good results in the levels of power and trends. A difference between these two results is observed, but it is reasonable because the dimensions and properties used in both models are somewhat different. 


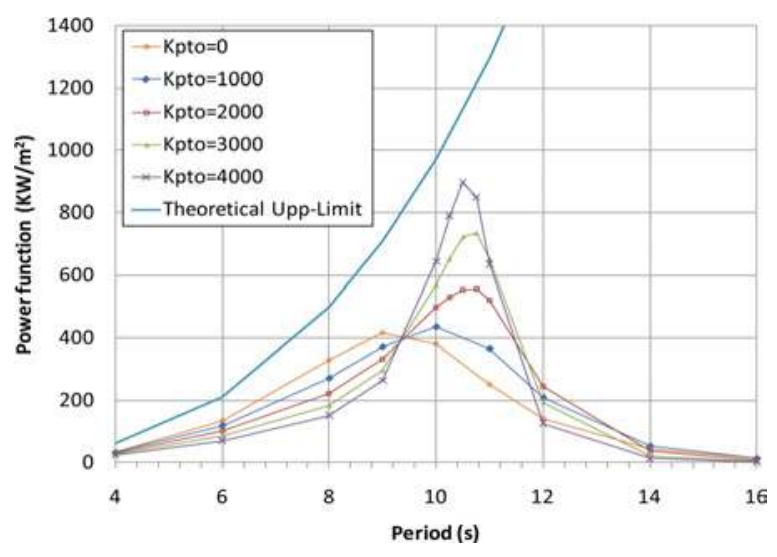

Fig. 18 The power function as a function of the Kpto coefficients $(B p t o=4000 \mathrm{kN} / \mathrm{m} \mathrm{s}$ and Mpto $=0$ ) obtained by simulation sets 7 to 10 in Table 3

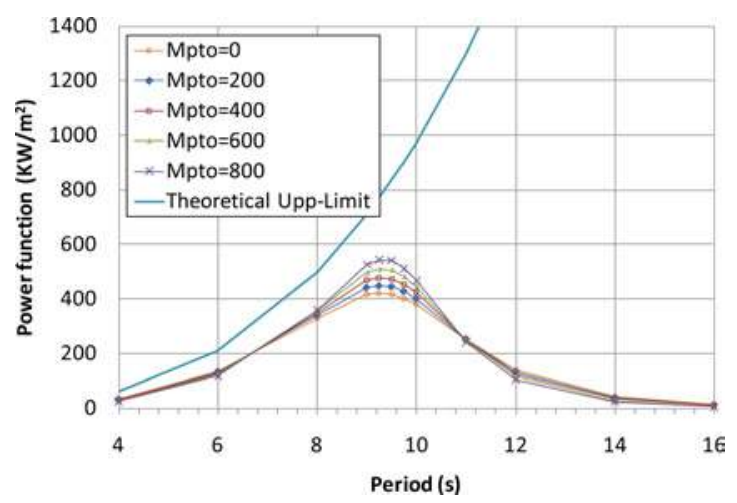

Fig. 19 The power function as a function of Mpto coefficients $($ Bpto $=4000 \mathrm{kN} / \mathrm{m} \mathrm{s}$ and Kpto $=0$ ) obtained by simulation sets 11 to 14 in Table 3

$$
\overline{P a} \leq \frac{1}{k} J_{E}
$$

where $\overline{P a}$ is the theoretical upper limit of absorbed power, and $k$ and $J_{E}$ are the wave number and wave power level, respectively.

When the Kpto coefficient is increased in simulation sets 7 to 10 in Table 4, the peak of power increases and shifts. Moreover, the system bandwidth becomes narrower. As shown in Fig. 18, the effect of an increase in Kpto is similar as in Bpto. However, one should notice that the power at peak may be larger when Kpto is increased. This increase is possible because the peak shift to the right in the Kpto case is larger than the Bpto case.

In Fig. 19 the effect of Mpto, which represents the transferred mass from Float to Torus, on power absorption can be observed. Compared to the effect of varying the PTO coefficients (Bpto and Kpto), a relatively small improvement on maximum power is observed when Mpto is increased. However, the system bandwidth becomes less narrow when the Mpto is varied.

The effect of end stops on motions is investigated by performing simulations with and without end stops. Figure 20 provides a general idea about what occurs when the relative motion between two bodies exceeds the end stops distance. If there is no end stop, the Torus movement will follow wave elevation, and the Float will move much less than the Torus. However, very different motions will occur when end stops are available within a narrow range of $\pm 0.5 \mathrm{~m}$ shown in Fig. 20. For the narrow end stop setting, the Torus will move freely only within end stop limits. If the relative motion is larger than the limit, then the Torus will carry the Float to follow its motion until the balance condition between the waves force on the Torus and the weight of the device is reached. When the Torus stops, however, the Float will continue to move slightly due to the remaining force. This movement occurs due to the small hydrodynamic stiffness of the Float and the much higher wave forces on the Torus. Knowing this feature, one can expect that the end stop distance will significantly influence the power capture of the device.

Further simulations are performed, and the results are plotted in Figs. 21 and 22. Figure 21 shows how the heave RAO for both bodies increases significantly when the distance of the end stop decreases. Moreover, compared to the $3-\mathrm{m}$ end stop case, the peak period is shifted to approximately $10 \mathrm{~s}$ in more narrow distances. This is consistent with the heave RAO of the WEC when the Torus and the Float are locked or are connected with very high damping that is presented in Fig. 15. If the end stop distance is set to be zero, both bodies will move together as a single body, and similar motions will be produced as if both bodies are connected with a very high Bpto.

In contrast to the heave RAO of the system, Fig. 22 shows that power captures significantly decreases when the end stop distance is decreased. This decrease occurs because the relative velocity between the two bodies is very small when they move together after the end stop distance is exceeded.

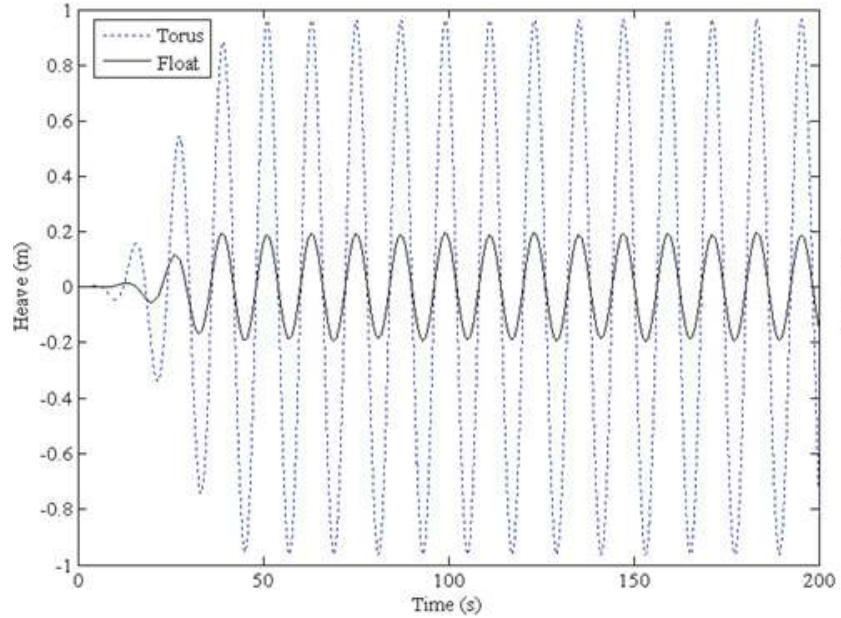

(a)

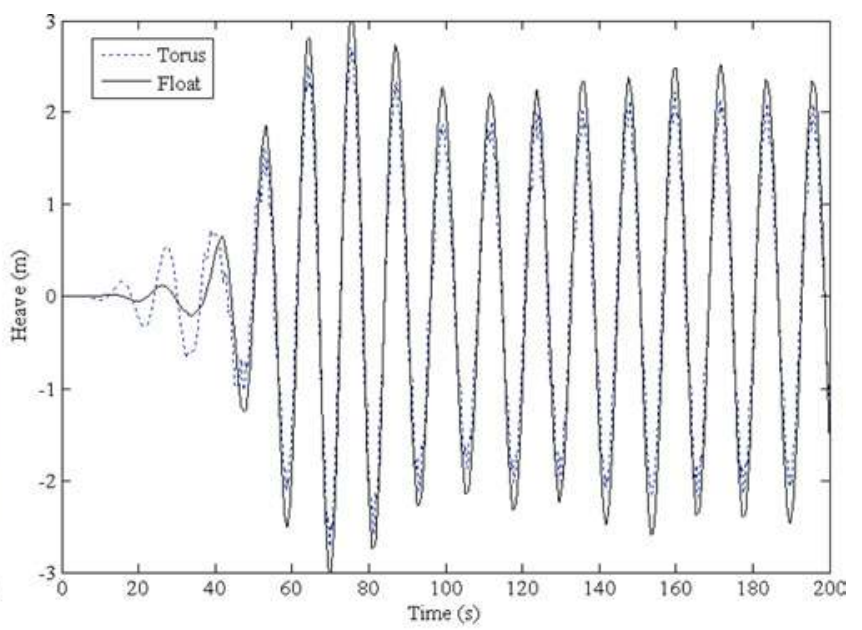

(b)

Fig. 20 Heave motions of the Torus and Float (a) without end stops and (b) with end stops set with a distance $0.5 \mathrm{~m}$. The simulations are run with an $H=2 \mathrm{~m}$ and $\mathrm{a} T=12 \mathrm{~s}$ without PTO coefficients $(B p t o=K p t o=M p t o=0)$. 


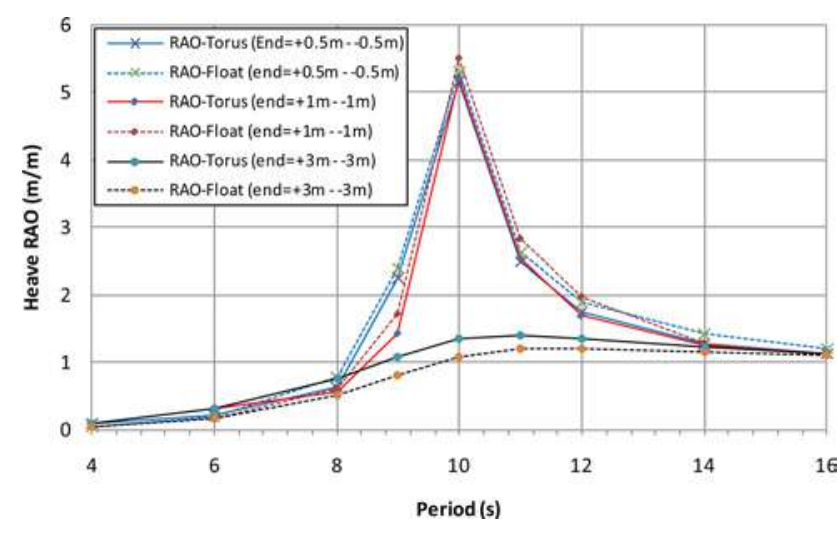

Fig. 21 Heave RAO of the Torus and Float with different end stop sets. The simulations are run with an $\mathrm{H}=7 \mathrm{~m}$ and a Bpto $=4000 \mathrm{kN} \mathrm{s} / \mathrm{m}$. (Kpto $=$ Mpto $=0)$.

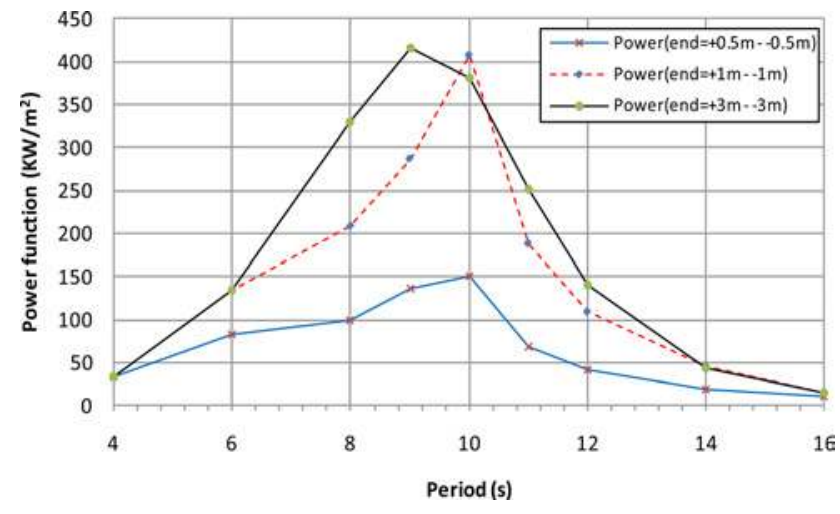

Fig. 22 The power function in different end stop sets. The simulations are run with an $H=7 \mathrm{~m}$ and a Bpto $=4000 \mathrm{kN} \mathrm{s} / \mathrm{m}$ $($ Kpto $=$ Mpto $=0)$.

Response in Regular Waves With Mooring. Nonlinear effect of the mooring to the heave motion of the device is illustrated in Fig. 23. With mooring, heave motion amplitude decreases when wave height decreases, especially around the maximum power output period. However, the heave motion remains as a dynamic harmonic response with one frequency. Other nonlinear effects due to the mooring are illustrated in Fig. 24. Using the same Bpto in the same wave period, the average power changes with an increase in wave height. This phenomenon will not be observed if no mooring is introduced. Therefore, it is important to include the mooring system in the analysis.

Complete simulations for each mooring configuration, which are described in Fig. 3 and Table 2, have been performed in several wave conditions to investigate their effect on power absorption. The results are presented in Figs. 25 and 26. Figure 25(a) shows that when relatively short lines are used in $\mathrm{MC}$, a clear trend in power behavior is observed. An increase in wave height in this configuration will slightly shift the peak to a lower period. When $T=9.5 \mathrm{~s}$ is used as a reference, then the average power in the higher wave period will decrease, and oppositely, power in the lower period will increase slightly with an increase in wave height. However, the results with MC4, which uses longer lines, shows no shifting in the peak period (Fig. 25(b)). Their power level also does not change significantly in wave height because the line stiffness does not start to work. Other simulation results with applications of MC2 $(L=235,240$, and 250) and MC3 are not presented in the paper. However, they show similar results in trend and power level for the results of the application of MC4, which are shown in Fig. 25(b).

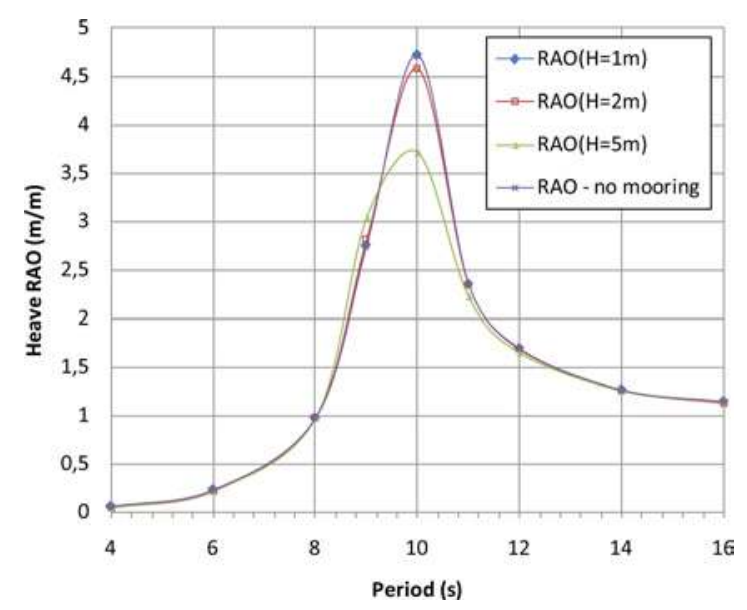

Fig. 23 Heave RAO of the combined bodies (high Bpto is applied with $\mathrm{Kpto}=\mathrm{Mpto}=0$ ) with $\mathrm{MC} 1$ configuration as a function of wave height

In Fig. 26, the power that was captured by the different mooring configurations is compared in different sea states. For the case with MC1, which that has the shortest lines of the specified mooring configuration in the present study, the power production is very sensitive to wave height. One can expect that the application of MC1 in this kind of WEC will influence the power capture more than any of the other configurations. Conversely, power with the MC2 $(L=240 \mathrm{~m}), \mathrm{MC} 2(L=250 \mathrm{~m})$, MC3 and MC4 configurations are quite stable during wave height changes. This stability occurs because these configurations use quite long mooring lines compared to their motions. However, it can be concluded from these results that the mooring configurations considered in the present study change the average power absorption of the device in regular waves by $+4 \%$ to $-8 \%$ compared to cases with no mooring.

Responses in Irregular Waves-Comparisons With and Without Mooring. To estimate the 1-year power production with and without mooring, a full year wave data taken at Yeu Island, France as illustrated in Fig. 4 is used in the present analysis. It is assumed that wave conditions are represented by a Jonswap wave spectrum with parameter $\gamma=3.3$. Only MC1 and MC3 configurations are considered in simulations with irregular waves. Only one setting of PTO is applied, namely Bpto $=8000 \mathrm{kN} \mathrm{s} / \mathrm{m}$ with no Kpto and Mpto, in the present study. A full year of sea states present at the site is considered as operational conditions; therefore, no locking settings between the two bodies are applied in the present power estimation.

The power distributions at the site that resulted from the WEC with different mooring conditions are presented in Fig. 27. Power productions for 1-year irregular wave conditions are summarized in Table 5. These quantities are derived from the results of 1200-s duration simulation results, with a time step of $0.01 \mathrm{~s}$. To remove the transient effects, the results of first 15 and 1 last peak periods are not taken into consideration. As shown in Fig. 27, only a small difference between the occurrence of power distribution by the WEC with MC1 and MC3 configurations is observed. The distribution of power by the WEC with no mooring is not presented here, but it is well represented by the distribution in Fig. 27(b). From these distributions, one can expect that the locking of settings between two bodies when wave height is higher than $6 \mathrm{~m}$ will not affect the power production of the device at the site. This result simply supports the locking assumption during extreme conditions that was used in the mooring analysis in the present study.

From the simulation, the Wavebob-type WEC produced around $220 \mathrm{~kW}$ during a full year of service at the given site is estimated. 


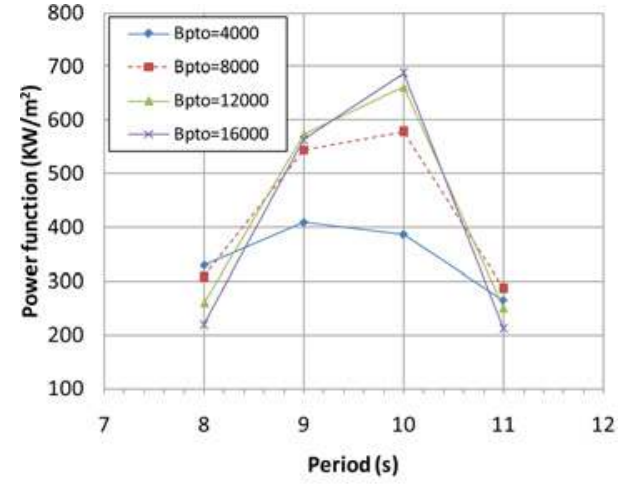

(a)

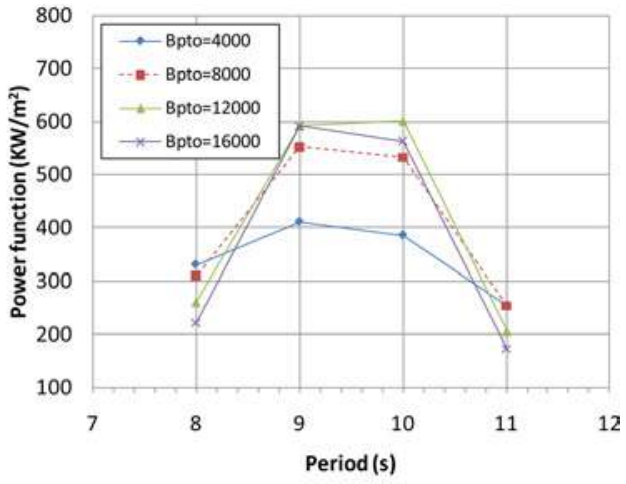

(b)

Fig. 24 The power function as a function of Bpto with MC1 configuration for various wave periods where (a) with $H=1 \mathrm{~m}$ and $(b)$ with $H=7 \mathrm{~m}$, respectively (Kpto $=$ Mpto $=0$ )

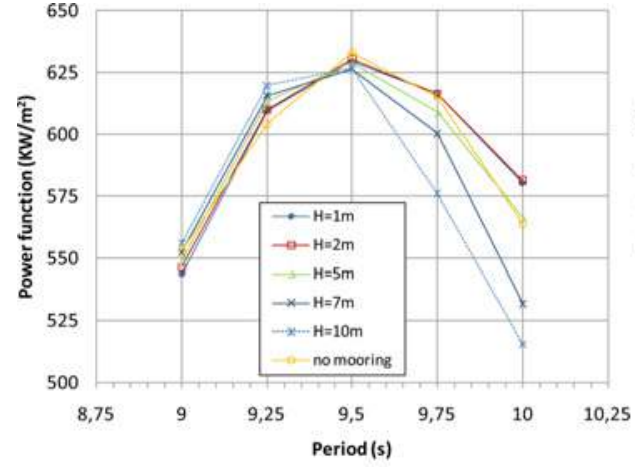

(a)

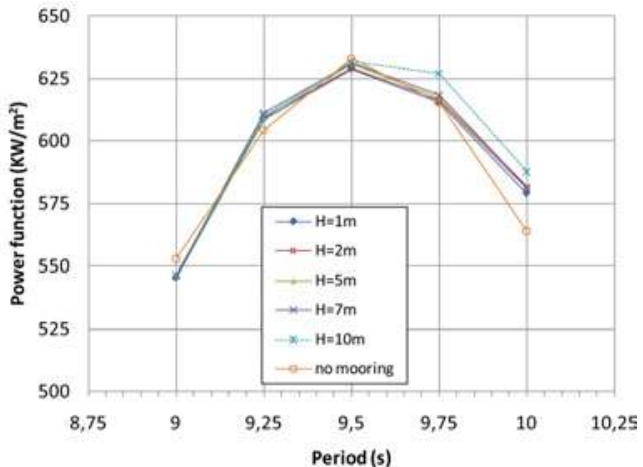

(b)

Fig. 25 The power function behavior near the maximum power output period in several waves conditions using Bpto $=8000 \mathrm{kN} \mathrm{s} / \mathrm{m}$ and $\mathrm{Kpto}=\mathrm{Mpto}=0$ when (a) MC1 and $(b) \mathrm{MC} 4$ configurations are introduced, respectively. Please refer to Fig. 2 and Table 2 for configuration properties.

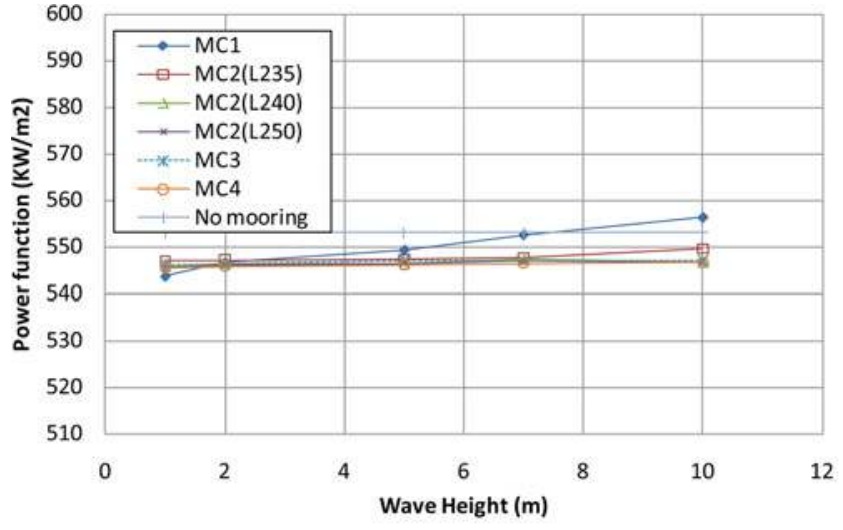

(a)

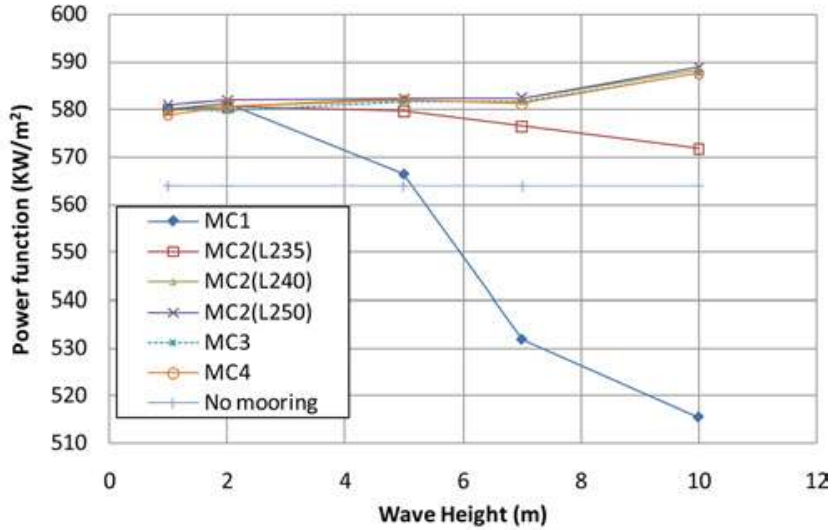

(b)

Fig. 26 Comparison of the power function effected by different mooring configurations at wave period (a) $9 \mathrm{~s}$ and (b) $10 \mathrm{~s}$, respectively. Simulations performed using Bpto $=8000 \mathrm{kN} \mathrm{s} / \mathrm{m}, \mathrm{Kpto}=\mathrm{Mpto}=0$.

This is consistent with power production ranges estimated by Babarit et al. in [17]. However, it should be noticed that the simulations used to estimate the power in the present paper do not include any viscous force on the WEC bodies. Therefore, smaller power should be expected in a real case when viscous forces on bodies are present.

Compared to the no mooring case, a year of power production at Yeu will decrease by approximately 2.5 and $0.2 \mathrm{~kW}$ due to the applications of MC1 and MC3, respectively. This is per observa- tion in regular wave conditions in which the mooring configuration of MC1 produces a larger effect on power production than MC3. However, the reduction of $2.5 \mathrm{~kW}$ by the MC1 configuration is only around $1.1 \%$ of total production, which is a small quantity. In addition to the PTO setting, the reason for this small reduction is because the occurrence of a high sea state at the Yeu site is very small. However, the effect of the mooring system on energy capture is expected to be larger at a site that has more occurrences of high sea states. 


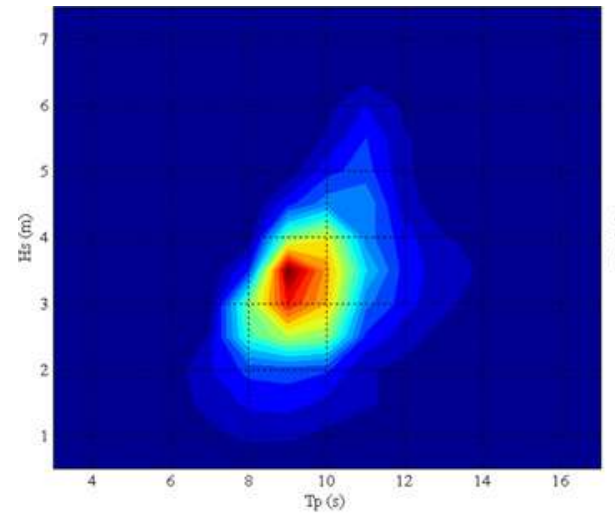

(a)

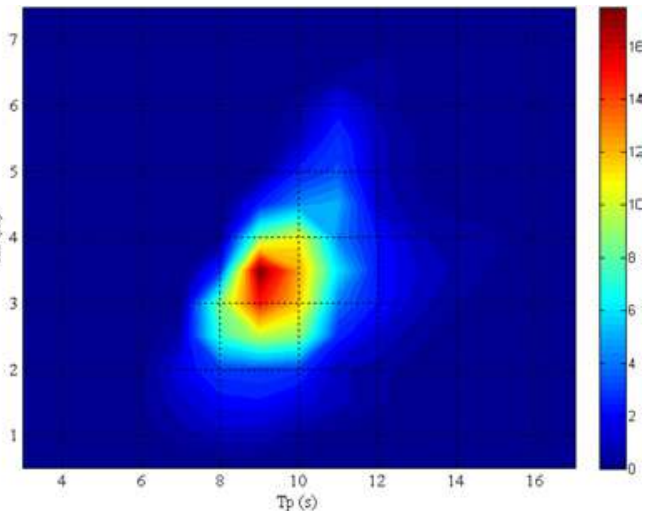

(b)

Fig. 27 Power production (kW) as a function of $H_{s}$ and $T_{p}$ at Yeu by the WEC with the (a) MC1 and $(b)$ MC3 configurations, respectively. Simulation performed using Bpto $=8000 \mathrm{kN} \mathrm{s} / \mathrm{m}$, Kpto $=$ Mpto $=0$.

Table 5 Average long-term power production at the Yeu site with different mooring configurations with the actual and an artificial uniform joint density function (scatter diagram) of sea states

\begin{tabular}{|c|c|c|c|c|c|}
\hline & \multirow{2}{*}{$\frac{\text { No mooring }}{\text { Mean power }(\mathrm{kW})}$} & \multicolumn{2}{|c|}{$\mathrm{MC} 1$} & \multicolumn{2}{|c|}{ MC3 } \\
\hline & & Mean power $(\mathrm{kW})$ & $\operatorname{Diff}(\mathrm{kW} / \%)$ & Mean power $(\mathrm{kW})$ & Diff $(\mathrm{kW} / \%)$ \\
\hline As scatter diagram & 217.5 & 215.0 & $2.5(1.1 \%)$ & 217.3 & $0.2(0.1 \%)$ \\
\hline With uniform distribution (artificial) & 333.8 & 316.4 & $17.4(5.2 \%)$ & 333.2 & $0.6(0.2 \%)$ \\
\hline
\end{tabular}

To determine the robustness of $\mathrm{MC} 1$ and $\mathrm{MC} 3$ in a higher occurrence of high sea states to power production, the artificial constant joint density function of Yeu's sea states is applied. This results in a more significant power reduction of $17.5 \mathrm{~kW}$ due to $\mathrm{MC} 1$. However, the application of MC3 in this uniform case only decreases the power by $0.6 \mathrm{~kW}$, which still amounts to almost no effect on annual power production. This certainly confirms that MC3 is insensitive to available wave height, and this is one alternative for the mooring configuration that should be applied at Yeu.

\section{Discussion and Conclusions}

Time domain simulations have been performed to study the effect of PTO coefficients, end stops, and several mooring configurations on power production by a two-body axisymmetric Wavebob-type WEC. The dimensions and parameters of the device have been estimated from available sources in present study. For this reason, the results presented in this paper may be different from the true Wavebob WEC project. Based on this study, the following conclusions can be made:

- An increase in PTO damping will increase the peak of power and will shift the peak to a higher wave period until a certain period is reached. After this period, no more shifting on the peak result by increase in damping, but an increase in peak power is continuously observed up to theoretical maximum. However, an increase in power on peak is followed by a narrowing of the bandwidth of the WEC system. In other words, an increase in PTO damping will increase power absorption near the maximum power output period but will decrease the power outside of the peak area. Therefore, the optimization of PTO damping should be made for the overall bandwidth that is available at the operation site to optimize power production, especially if a constant damping quantity will be applied during the overall production period. Alternatively, the application of the successful active control on PTO damping should greatly benefit the power that is captured by this kind of device.
- An increase in and shift of peak power and a narrowing of the bandwidth are also observed when the stiffness of the PTO system is increased, as in damping cases. However, possible higher levels of power at peak can be reached by an increase in stiffness rather than by damping. This higher level of power is possible because the peak shift to a larger period than the damping case. Similar to the damping case, the application of a control strategy on PTO stiffness will be a challenge for the improvement of power production.

- A relatively small improvement in peak power is observed when the amount of transferred mass from the Float to the Torus is increased. However, the positive side of the increase in this mass is a much lower narrowing effect on system bandwidth. Therefore, the control of this quantity will be much easier than the control of the damping and stiffness of the PTO, which can be performed by increasing this mass as much as possible with consideration of the Torus volume and the stability of the device as the limits.

- A significant change of the motion occurs when the relative motions between the Torus and the Float is larger than the setting of end stops. This condition also decreases power production significantly. To avoid this, one may set very large gaps between the end stops. However, this strategy will increase the cost of the PTO system and the structure that is required to accommodate very large power that only occurs in very short periods during survival conditions. Therefore, proper settings should be applied that take into account the sea state and PTO system settings during operational conditions. Generally, a broader stroke is needed in higher sea states, but a more narrow end stop setting should be enough when large quantities of PTO coefficients are applied. However, economical optimization should be made prior to decide the end stops setting that is corresponding to the maximum power that will be harvested.

- The mooring analysis that includes the second order wave force performed to determine the necessary capacity of the mooring line for each specified mooring configuration to 
carry the tension due to WEC motion in extreme conditions. The contour line method has been adopted to estimate the long-term extreme mooring tension. The ultimate limit state (ULS) criteria, as specified in [7] for oil and gas structures, has been considered for the mooring line design. Based on the line dimension results from the analysis, the effect of the specified mooring system properties and the configurations to the power captured has been studied. Only first order wave forces have been included in the estimation of the power capture. The effect of mooring on motions and power will significantly depend on its configuration and sea state condition. Due to the nonlinear character of the mooring stiffness, the influence of the mooring will increase by an increase in sea severity and a decrease in line length. From the present simulation, it is observed that as long as the length of the mooring lines can accommodate the motions of the device due to first order wave forces, especially in heave for this Wavebob-type WEC, the effect of the mooring will be insignificant. This observation answers the statement made by Johanning and Wolfram [18] of the ideal mooring system for motiondependent WEC. They mentioned that an ideal mooring system for the WEC that would be stiff enough to restrict displacements due to steady forces but allow motion response to first order wave loading without the tension being too great.

There are still many remaining challenges related to the analysis of two-body WEC with mooring to optimize the economical value of WEC that need further investigation. The challenges will include, but are not limited to, the viscous damping effects, the application of buoy or clamp weight on mooring lines, mooring analysis of the WEC farm, fatigue damage estimation, and cost optimization. However, these issues could form part of a future study.

\section{Acknowledgment}

The first author gratefully acknowledges the support of the EU-Wavetrain2 project and the Research Council of Norway
(RCN) for funding. We thank the RCN for their financial support through the Centre for Ship and Ocean Structures.

\section{References}

[1] French, M. J., 2006, "On the Difficulty If Inventing an Economical Sea Wave Energy Converter: A Personal View,” J. Eng. Mar. Environ., 22(M), pp. 149-155.

[2] Fitzgerald, J., and Bergdahl, L., 2007, "Including Moorings in the Assessment of a Generic Offshore Wave Energy Converter: A Frequency Domain Approach," Mar. Struct., 21, pp. 23-46.

[3] www.wavebob.com, last accessed November 30, 2010.

[4] Mouwen, F., 2008, "Presentation on Wavebob to Engineers Ireland. December 9, 2008," downloaded from www.engineersireland.ie, last accessed September $10,2010$.

[5] CANDHIS Wave Data Base chandis.cetmef.develppement_durable.gouv.fr.

[6] http://maps.google.no, last accessed May 16, 2011.

[7] Det Norske Veritas (DNV), 2006, Position Mooring, Offshore Standard, DNVOS301.

[8] Winterstein, S. R., Ude, T. C., Cornell, C. A., Bjerager, P., and Haver, S., 1994, "Environmental Parameters for the Extreme Response: Inverse FORM With Omission Factors," Proc. ICOSSAR-1993, Balkema, Rotterdam, pp. 551-557.

[9] DNV, 2004, HydroD User Manual, Program Version 1.1-01.

[10] WAMIT, 2006, User Manual, Program Version 6.3, www.wamit.com.

[11] Riflex Manual, http://www.sintef.no/Home/Marine/MARINTEK/Softwaredeveloped-at MARINTEK/RIFLEX/.

[12] Norsok Standard N-003, Edition 2, Sept 2007.

[13] Haver, S., Sagli, G., and Gran, T. M., 1998, "Long Term Response Analysis of Fixed and Floating Structures," Proc. of the 1998 International OTRC Symposium, Houston, TX.

[14] Johanning, L., and Wolfram, J., 2006, "Mooring Design Approach for Wave Energy Converters," Proc. IMechE Part M, 220, pp. 159-174.

[15] Marintek, 2008, SIMO User Manual, Program Version 3.6.

[16] Budal, K., and Falnes, J., 1975, “A Resonant Point Absorber of Ocean," Nature, 256, pp. 478-479, with F. Corrigendum in 257, p. 626.

[17] Babarit, A., Hals, J., Muliawan, M. J., Kurniawan, A., and Moan, T., 2012, "Numerical Benchmarking Study of a Selection of Wave Energy Converters," Renew. Energy, 41, pp. 44-63.

[18] Johanning, L., and Wolfram, J., 2005, "Challenging Tasks on Moorings for Floating WECs," Proceedings of the International Symposium on Fluid Machinery for Wave and Tidal Energy (IMechE), London, UK. 